\title{
Pressure fluctuation study in the stages of a multistage pump at best efficiency points under various operating speeds
}

\author{
Dhanasekaran Arumugam* and Kumaraswamy Sivasailam ** \\ * Professor, Center for Energy Research, Department of Mechanical Engineering, Chennai Institute of Technology, Chennai, India. \\ ** Former Professor, Department of Mechanical Engineering, Indian Institute of Technology Madras, Chennai, India. \\ **Corresponding Author: s.kumaraswamy@gmail.com
}

$\begin{array}{ll}\text { Submitted } & : 14 / 04 / 2020 \\ \text { Revised } & : 28 / 03 / 2021 \\ \text { Accepted } & : 11 / 04 / 2021\end{array}$

\begin{abstract}
The interaction between the rotor and stator is a major source of high amplitude pressure fluctuation and flowinduced vibration in multistage centrifugal pumps. the pressure fluctuation is detrimental to the reliable operation of pumps. The sensitivity of vibration is severe if the number of stages increases. In the present experimental study, a vertical multistage centrifugal submersible pump is used to measure the pressure fluctuation level at Best Efficiency Points (BEP) and to determine the influence of stage and operating speed on pressure fluctuation. For this purpose, pressure fluctuation signals were captured at the delivery side of the pump at BEP at various speed settings. The characteristics of pressure fluctuation at BEP at various operating speeds were studied with the help of spectra, that is, in the frequency domain. The amplitude variation of pressure fluctuation with harmonics of vane passing frequency at stages was studied. Results have indicated that the variation of pressure fluctuation with stage and speed exhibited a nonlinear variation. In addition, such a pressure fluctuation study will be helpful in modifying the design to obtain a uniform pressure distribution in the stages of a multistage pump.
\end{abstract}

Keywords: Best efficiency point; Diffuser casing; Harmonics; Multistage pump; Pressure fluctuation.

\section{INTRODUCTION}

Vertical multistage submersible centrifugal pumps are widely used in agriculture and petroleum wells. These pumps have the characteristics of developing high head and discharging large quantity of fluid. Owing to its high rotational speed of the impeller and dynamic and static interaction between impeller and diffuser vanes, the flow inside the pump is complex, unsteady, and turbulent in nature and causes pressure fluctuation to be generated inside the pump. The pressure fluctuation will lead to flow induced vibration and noise that will affect the operational reliability of centrifugal pumps. An excessive vibration can cause fatigue failure to the rotating machines and cause a catastrophic damage (Zhou et al., 2015). The wake flow from the trailing edge of impeller vanes, large-scale turbulence and vortices generated due to flow separation and recirculation are the main causes of pressure fluctuation in centrifugal pumps (Guelich \& Bolleter, 1992). Even at the Best Efficiency Point (BEP), pressure pulsation occurs due to the interaction between the impeller and the volute (Brennen, 1994). It has also been accepted that the 
distribution of flow field is not circumferentially uniform in the diffuser or volute. The unevenness in the flow field is not only due to geometrical parameters but also due to the operating condition of the pumps.

Several research works have been carried out to investigate the pressure fluctuation due to unsteadiness either by conducting experiments or by numerical simulation. The main objective was to find the effect of design parameters on the characteristics of pressure fluctuation (Spence \& Teixeira, 2009). The purpose of investigating pressure fluctuation was to explore the feasibility of modelling the rotor-stator interaction between the impeller and the diffuser vanes. Further, an effective approach can be postulated to attenuate pressure fluctuation during the design stage of centrifugal pumps which is the primary requirement of pump manufacturers and pump application engineers. Centrifugal pumps are designed to operate at their BEP as far as possible.

The BEP of centrifugal pumps can be found by conducting performance test. The value obtained at BEP from the tests can be used to compute various design and hydraulic parameters. The range of operation of centrifugal pumps are usually expressed as a percentage of BEP.

Numerical investigation using delayed detached Eddy simulation (DDES) was carried out by Zhang et al. (2020) to investigate the flow structures and pressure pulsations at off-design conditions in a low specific speed centrifugal pump. Liu et al. (2019) have experimentally measured the pressure fluctuation in a centrifugal pump with a vaneddiffuser. Luo et al. (2019) have carried out numerical simulation and experimental work on a low specific speed centrifugal pump to analyze the effect of baffles on pressure fluctuation. Posa and Lippolis (2019) carried out Large Eddy Simulations (LES) to investigate the effect on pressure fluctuations at various flow rates and diffuser blade orientation and concluded that pressure fluctuation was higher at lower flow rates. Wu et al. (2017) have conducted experimental investigation on pressure pulsations using the dynamic pressure transducers and by Particle Image Velocimetry (PIV). Liu et al. (2016) have investigated the effect of the inlet pressure on the cavitating turbulent flows in rotor pumps and found that the pressures at suction and the discharge side increase rapidly at some moment and produce pressure fluctuations.

Stel et al. (2015) conducted numerical investigation to analyze the flow in a multistage submersible pump to optimize the design. Experimental investigations were carried out by Christopher and Kumaraswamy (2013) on a radial flow pump for three different leading edge profiles of the impeller vane under cavitating conditions to correlate the noise and vibration. The flow induced noise due to back flow was experimentally investigated by Si et al. (2013) in a low specific speed centrifugal pump. Influence of blade orientation effects on turbulence was studied by Feng et al. (2009) using a radial diffuser pump with the help of Laser Doppler Velocimetry (LDV). Wang and Tsukamoto (2003) have investigated unsteady phenomenon in a diffuser pump at off-design condition by using experimental and numerical methods. However, the effect of change in operating speed and stage on pressure fluctuation in a vertical multistage submersible pump has not been reported. Therefore, the scope of this experimental study is to investigate the unsteady pressure fluctuation characteristics in a vertical multistage submersible pump at BEP at five operating speeds, which range from 0.8 to 1.2 of its nominal speed. A performance test was conducted to identify the BEP at various speeds.

\section{EXPERIMENTS}

A five-stage Electrical Submersible Pump (ESP), which is shown in Fig. 1, was selected for conducting experiments. The pump has similar impeller in all the five stages. Since the experiments must be conducted up to 20 $\%$ more than its nominal speed, this pump was assembled with a motor of higher rating to enable the pump to operate higher speeds. Figure 2 shows the drawing of impeller and diffuser in their assembled position. 


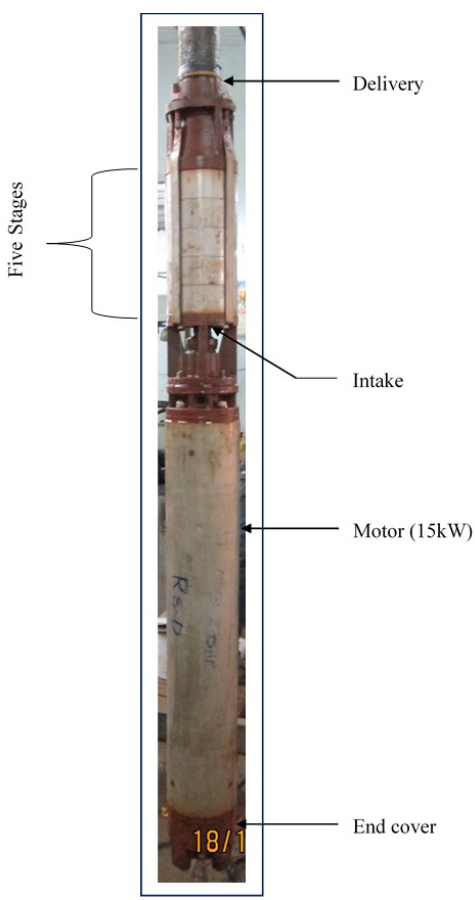

Figure 1. Five-stage ESP for conducting experiments.

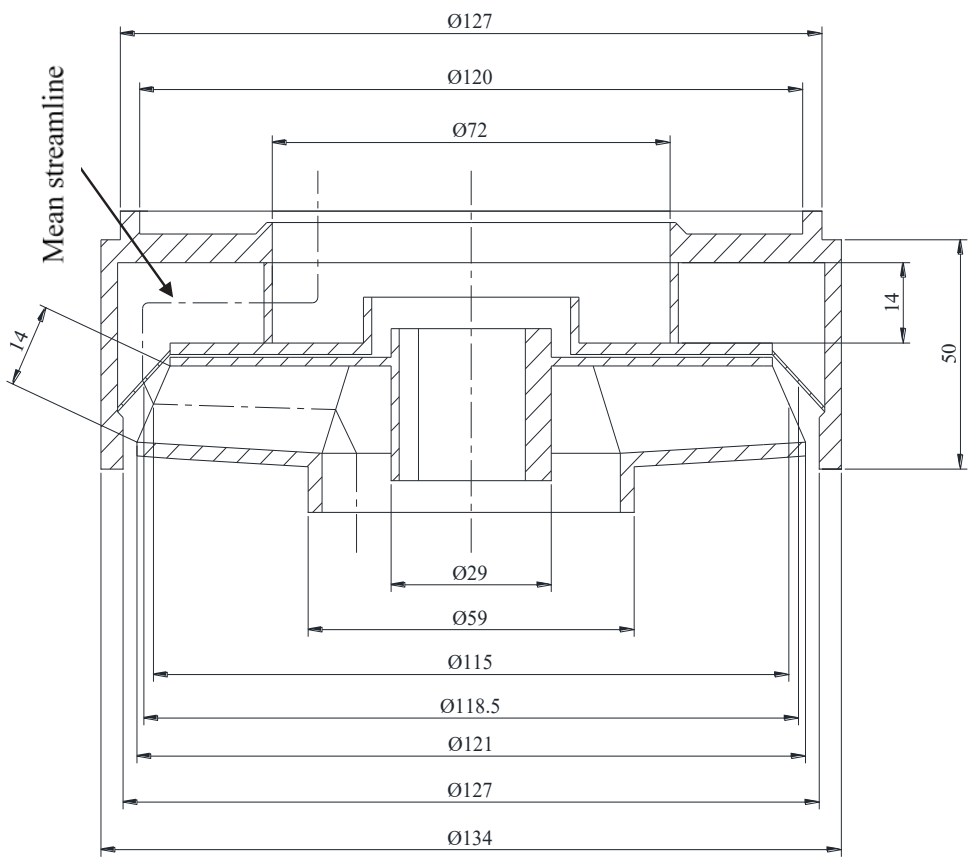

All dimensions are in $\mathrm{mm}$

Figure 2. Assembled view of impeller and diffuser. 
A Pulse Width Modulated (PWM) Variable Frequency Drive (VFD) rated for $20 \mathrm{HP}$ and 10 to $600 \mathrm{~Hz}$ frequency range was employed to operate the pump at various speeds. The geometrical and hydraulic parameters of the ESP are given in Table 1.

Table 1. Details of geometrical and hydraulic parameters of ESP.

\begin{tabular}{|c|c|c|}
\hline SI. No & Description & Range / Dimension \\
\hline 1 & Discharge (Q) at $50 \mathrm{~Hz}$ & 7 lps (liters per sec) \\
\hline 2. & Head $(\mathrm{H})$ at $50 \mathrm{~Hz}$ & $60 \mathrm{~m}$ \\
\hline 3. & Impeller diameter $\left(\mathrm{d}_{2}\right)$ & $121 \mathrm{~mm}$ \\
\hline 4. & Width of vane at inlet $\left(b_{1}\right)$ & $16 \mathrm{~mm}$ \\
\hline 5. & Width of vane at outlet $\left(b_{2}\right)$ & $14 \mathrm{~mm}$ \\
\hline 6. & Number of impeller $\left(\mathrm{z}_{\mathrm{i}}\right)$ vanes & 8 \\
\hline 7. & Number of diffuser $\left(z_{d}\right)$ vanes & 6 \\
\hline 8. & $\begin{array}{l}\text { The diameter of impeller vane }\left(\mathrm{d}_{\mathrm{m} 2}\right) \text { at mean } \\
\text { streamline }\end{array}$ & $115 \mathrm{~mm}$ \\
\hline 9. & $\begin{array}{l}\text { The diameter of diffuser vane }\left(\mathrm{d}_{\mathrm{m} 3}\right) \text { at mean } \\
\text { streamline }\end{array}$ & $118.5 \mathrm{~m}$ \\
\hline 10. & Diameter ratio $\left(\mathrm{d}_{\mathrm{m} 3} / \mathrm{d}_{\mathrm{m} 2}\right)$ & 1.03 \\
\hline
\end{tabular}

\section{Performance tests at various speeds}

A recirculating test loop as shown in Fig. 3 with clear water at room temperature as working fluid was designed and erected according to the Indian Standard IS: 9137 (1978). Performance tests were conducted at five speed settings of $0.8,0.9,1.0,1.1$, and 1.2 of nominal speed. Delivery pressure $\left(\mathrm{P}_{\mathrm{d}}\right)$ was measured using an analog pressure gauge and a digital pressure transmitter. A three-phase power analyzer was used to measure input power $\left(\mathrm{P}_{\text {in }}\right)$ supplied to the motor via VFD. Flow rate was measured using a turbine flow meter. The details of the instruments used to conduct experiment are given in Table 2. The energy available at the suction was subtracted while calculating the head developed by the pump. The motor and the pump assembly were submerged under water, so the output power and speed of the motor could not be measured directly. Therefore, the actual speed ( $\left.\mathrm{N}_{\text {actual }}\right)$ of operation of the pump was estimated from the values of slip and input power values (Dhanasekaran \& Kumaraswamy, 2017). 


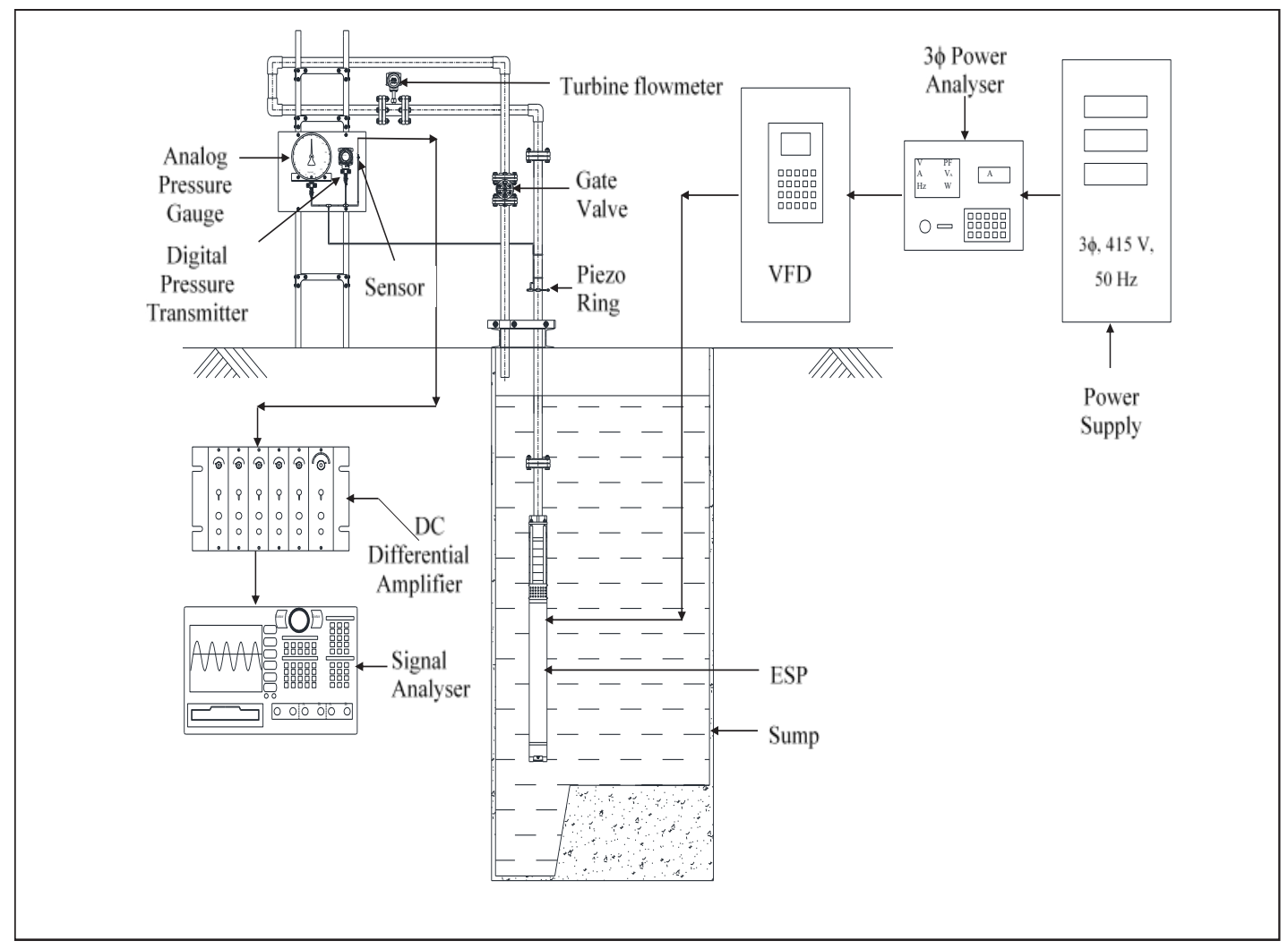

Figure 3. Layout of experimental setup.

From the values obtained from the performance test, nondimensional parameters such as head coefficient $(\psi)$ and flow coefficient $(\varphi)$ were calculated, and performance characteristics curves were drawn for all speeds and are shown in Fig. 4. The measured and calculated hydraulic parameters at BEP are given in Table 3.

Table 2. Details of instruments used for experiments.

\begin{tabular}{|c|c|c|}
\hline Instrument & Range & Accuracy \\
\hline Pressure gauge $\left(\mathrm{P}_{\mathrm{d}}\right)$ & $0-25 \mathrm{kp} / \mathrm{cm}^{2}$ & $\pm 0.05 \mathrm{kp} / \mathrm{cm}^{2}$ \\
\hline Pressure transmitter & $0-20 \mathrm{bar}$ & $\pm 0.0025 \mathrm{bar}$ \\
\hline Turbine flowmeter $(\mathrm{Q})$ & 16.67 lps (litres per sec) & $\pm 0.016 \mathrm{lps}$ \\
\hline Power analyzer $\left(\mathrm{P}_{\text {in }}\right)$ & $0-20 \mathrm{~kW}$ & $\pm 1 \mathrm{~W}$ \\
\hline
\end{tabular}

These performance characteristic curves were compared with the characteristic curves obtained by Rakibuzzaman et al. (2015), Xia et al. (2015), and Fiaschi et al. (2005). From the comparison, it was concluded that the head versus discharge characteristic of the pump was stable under variable speed operation. 


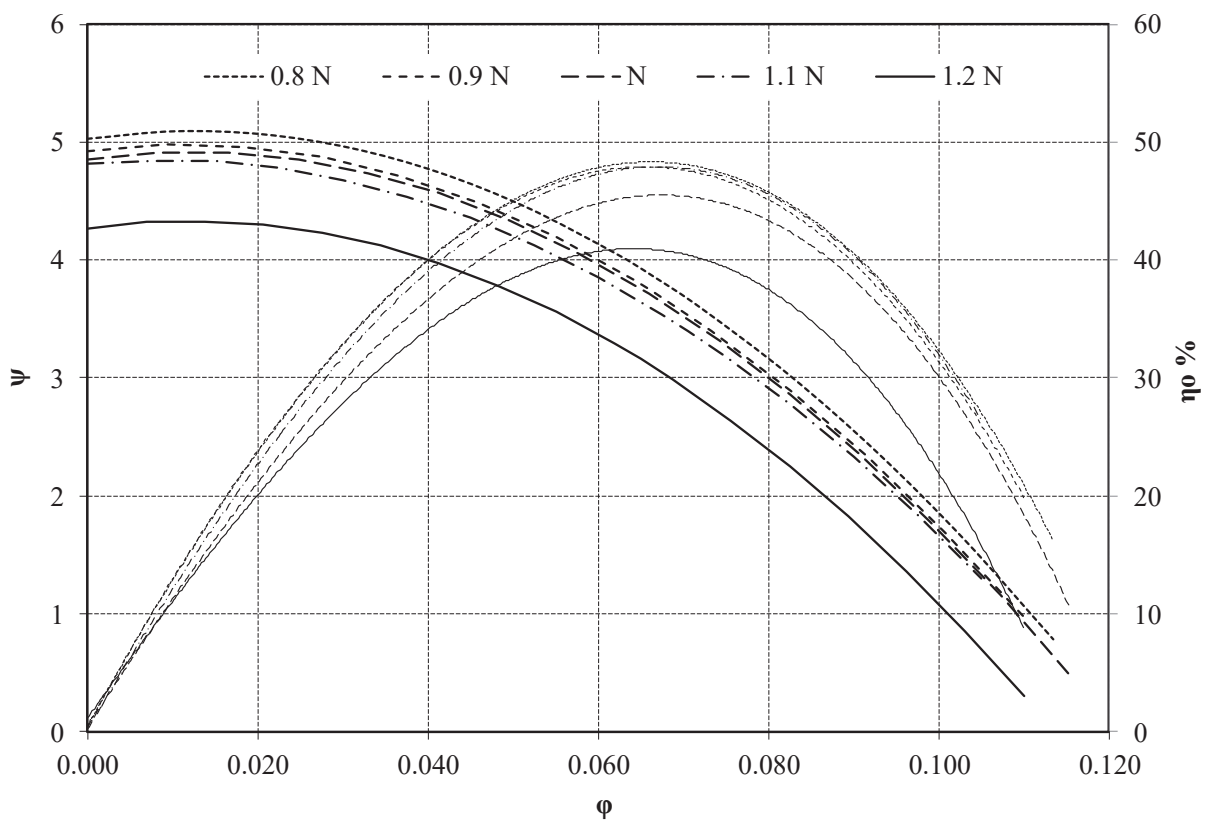

Figure 4. Performance characteristics curves of the pump at all speeds.

Table 3. Measured and calculated parameters at BEP at various speeds.

\begin{tabular}{|c|c|c|c|c|c|c|}
\hline $\mathbf{N}$ & $\mathbf{H}$ & $\mathbf{Q}$ & $\mathbf{P}_{\text {in }}$ & $\mathbf{N}_{\text {actual }}$ & $\boldsymbol{\eta}_{\mathbf{o}}$ & $\mathbf{N}_{\text {sh }}$ \\
\hline $\mathrm{Hz}$ & $\mathrm{m}$ & $\mathrm{lps}$ & $\mathrm{kW}$ & $\mathrm{Hz}$ & $\%$ & \\
\hline 40 & 45.51 & 5.37 & 5.00 & 39.84 & 48.07 & 100.91 \\
\hline 45 & 55.68 & 6.03 & 6.90 & 44.60 & 47.73 & 103.43 \\
\hline 50 & 66.66 & 6.87 & 9.91 & 48.82 & 45.30 & 107.13 \\
\hline 55 & 78.81 & 7.49 & 12.10 & 53.34 & 47.86 & 108.58 \\
\hline 60 & 82.79 & 7.87 & 16.01 & 60.49 & 40.34 & 116.98 \\
\hline
\end{tabular}

A nondimensional parameter shape number $\left(\mathrm{N}_{\text {sh }}\right)$ was calculated at various speeds. The value of $\mathrm{N}_{\text {sh }}$ at the nominal operating speed was 107.13 and at $0.8 \mathrm{~N}$ it was lower by 6.22 . At the highest speed of $1.2 \mathrm{~N}$, it was higher by 9.85 from the value obtained at nominal speed. The total variation of $\mathrm{N}_{\mathrm{sh}}$ was $15 \%$ for $\pm 20 \%$ variation in the operating speed. Such a variation in the shape number was found in the results of the tests conducted on four different impellers at various operating speeds by Kumaraswamy (1986), where the value of highest variation in shape number was found to be $7.71 \%$ for $\pm 13.33 \%$ speed variation.

The BEP required to capture pressure fluctuation were found from the performance test results. The uncertainty values based on the accuracy of the instruments at BEP when the pump was operated at nominal speed were \pm 2.44 $\%$ for $\mathrm{Q}, \pm 2.02 \%$ for Pin, $\pm 3.55 \%$ for $\mathrm{H}$ and $\pm 4.76 \%$ for $\eta$ o. 


\section{Pressure fluctuation measurement}

Pressure fluctuation was measured using a miniature piezo resistive transducer of sensitivity $0.352 \mathrm{mV} / \mathrm{psi}$ manufactured by Kulite. The pressure transducer was fixed at the discharge pipe of the pump through a sensor holder which was mounted in a separate tapping taken from the piezo-ring similar to the method followed by Robinett et al. (1999). A DC differential amplifier was used to amplify the pressure fluctuation signals. A dual channel network signal analyzer was used to acquire the signals which were sensed by the pressure transducer. A RF (Radio Frequency) connector was used

to transfer the signals from the differential amplifier to signal analyzer via BNC (Bayonet Neill-Concelman) cables.

The instrumentation scheme to capture pressure fluctuation is shown in Fig. 5. The instruments used to capture the signals are given in Table 4. At each speed setting, the pump was operated at its BEP, and the pressure fluctuation signals were captured at a sampling rate of $262.1 \mathrm{kHz}$ for 781 milliseconds in the dual channel network signal analyzer.

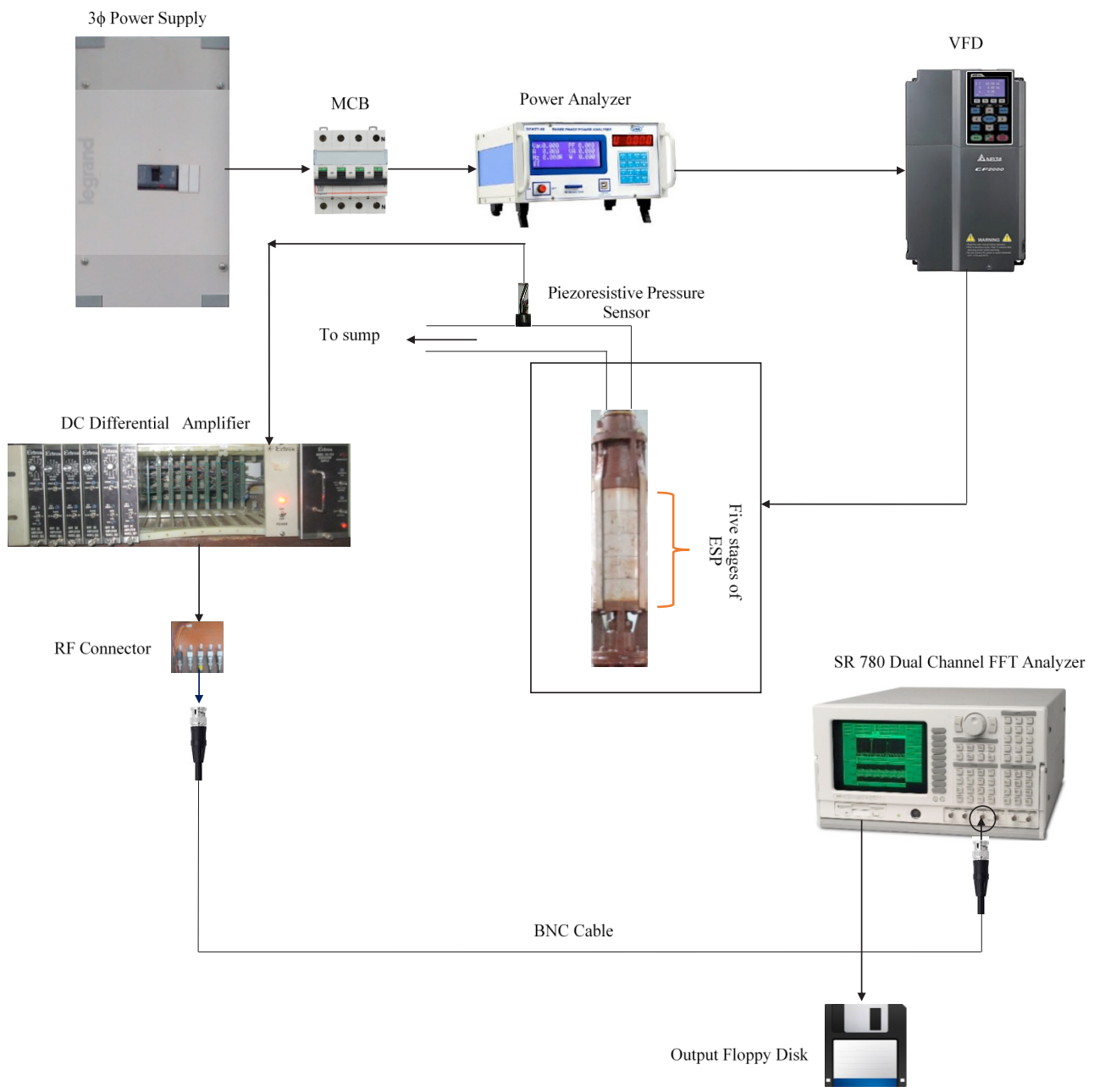

Figure 5. Instrumentation scheme for signal capturing. 
Table 4. Instruments used for capturing pressure fluctuation signal.

\begin{tabular}{|l|c|c|}
\hline \multicolumn{1}{|c|}{ Instrument } & Range & Accuracy \\
\hline Piezo resistive pressure sensor & $200 \mathrm{psi}$ & $0.352 \mathrm{mV} / \mathrm{psi}$ \\
\hline DC Differential amplifier & $80 \mathrm{kHz}$ & $\pm 3 \mathrm{~dB}$ \\
\hline Dual channel network Signal analyzer & $102.4 \mathrm{kHz}$ & $\pm 0.2 \mathrm{~dB}$ \\
\hline
\end{tabular}

\section{RESULTS AND DISCUSSION}

The pressure fluctuation signals captured from the sensor have 204800 samples. These samples were in the time domain and were in analog form. The pressure fluctuation signals were imported to MATLAB software, and the time-domain plots of variation of pressure fluctuation with time were drawn for all the speeds with time in milliseconds as abscissa and amplitude of pressure fluctuation in $\mathrm{Pa}$ as ordinate. The time domain plots of captured signals are shown in Fig. 6 (Figures 6a to 6 e). It may be noted that at nominal speed setting of $50 \mathrm{~Hz}$ if the impeller was rotating at $3000 \mathrm{rpm}$ then the time required for one complete revolution of the impeller will be 20 milliseconds. In this experiment pressure fluctuation signals were captured for 781 milliseconds, which corresponds to 39.05 cycles of impeller for a speed setting of $50 \mathrm{~Hz}$. A similar method was followed to find the cycle time required for one complete revolution of the impeller at other speeds.

From the captured data, the signals corresponding to two cycles were extracted according to the cycle time requirement at the respective speeds. Since the actual speeds as shown in Table 3 differ from the synchronous speed, the cycle time required for one complete revolution of the impeller differs from the value obtained from the synchronous speed (i.e., at $50 \mathrm{~Hz}$ speed setting the cycle time for one complete revolution of the impeller based on its actual speed of $48.82 \mathrm{~Hz}$ is 20.48 milliseconds). Hence, the cycle time for one complete revolution of the impeller was calculated based on the actual speeds and are represented separately in the same time domain plots of pressure fluctuation signals for two cycles drawn at various speeds. Figure 6 (Figures $6 \mathrm{f}$ to $6 \mathrm{j}$ ) shows the time domain plots of the signals extracted for two cycles at various speeds along with the marking of cycle time for one complete revolution of the impeller calculated based on the actual speed.

From figures 6 a to $6 \mathrm{e}$, it can be observed that the distribution of pressure fluctuation in the time-domain is similar at various speeds. However, the amplitude of pressure fluctuation is different at various operating speeds. This variation in the amplitude of pressure fluctuation is due to the jet-wake flow pattern at impeller exit, interaction between rotating and stationary components at various stages and interstage effects in the multistage pumps. The time-domain signals are mainly associated with the number of impeller blades. 


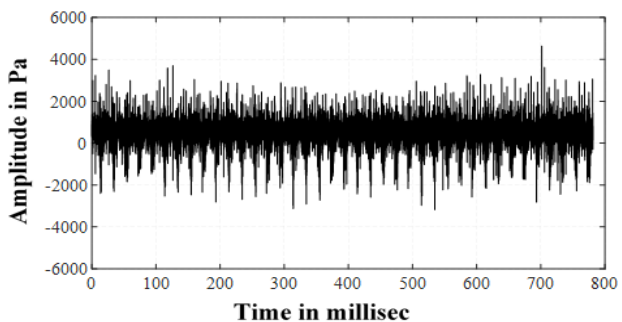

(a). At $0.8 \mathrm{~N}$

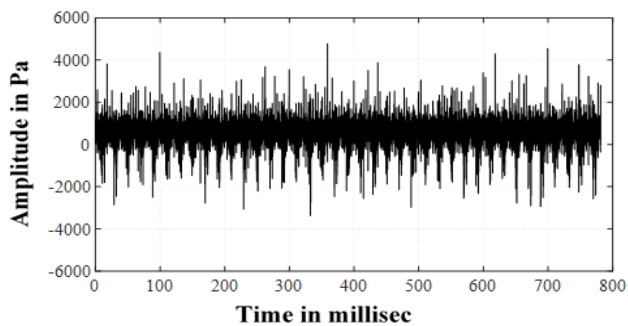

(b). At $0.9 \mathrm{~N}$

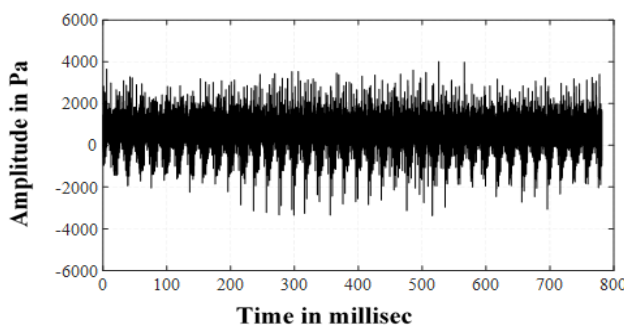

(c). At N

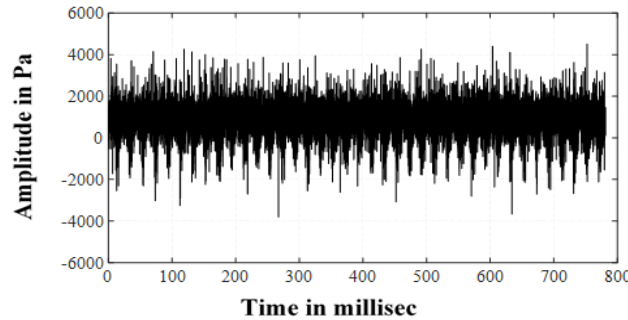

(d). At $1.1 \mathrm{~N}$

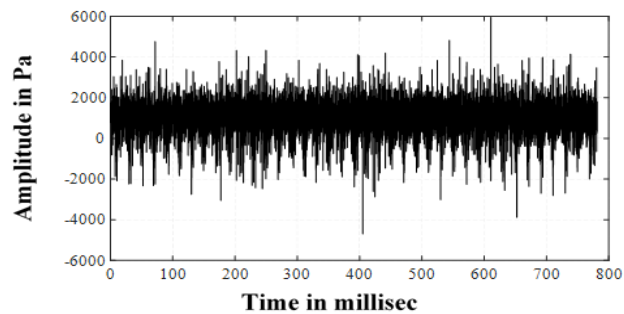

(e). At $1.2 \mathrm{~N}$

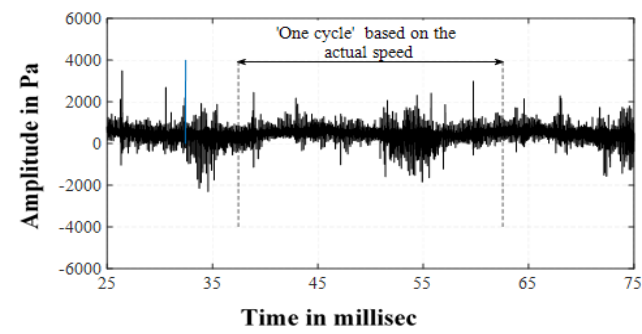

(f). At $0.8 \mathrm{~N}$

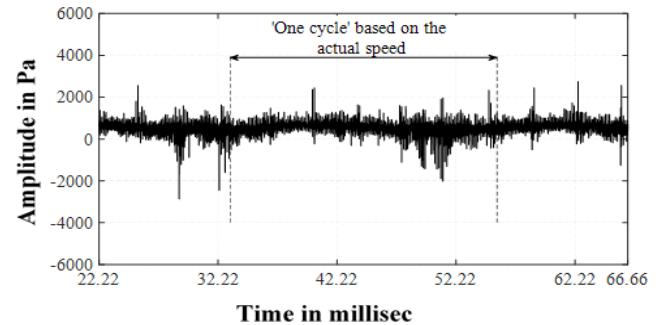

(g). At $0.9 \mathrm{~N}$

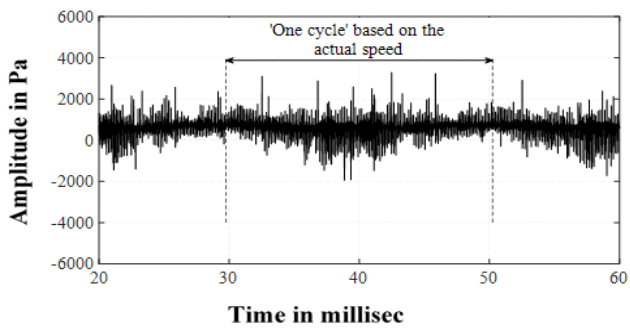

(h). At $\mathrm{N}$

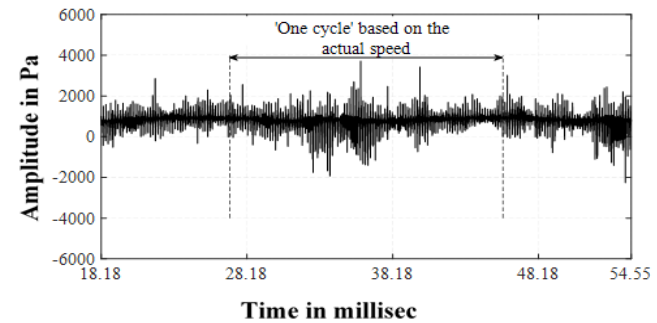

(i). At $1.1 \mathrm{~N}$

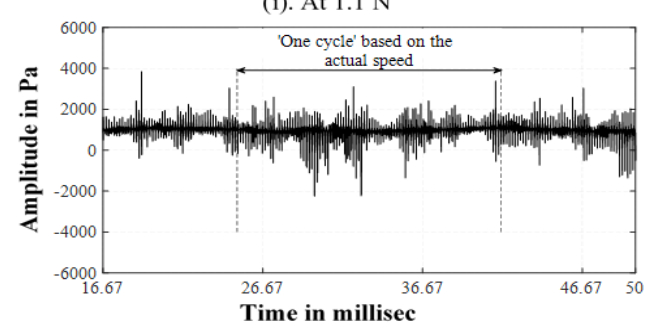

(j). At $1.2 \mathrm{~N}$

Figure 6. Time domain plot of captured pressure fluctuation signals (Figures 6 a to 6 e) and for two cycles along with the cycle time for one complete revolution of the impeller calculated based on the actual speed 
The pressure fluctuation signals in time domain for two cycles of impeller rotation which are shown in figures $6 \mathrm{f}$ to $6 \mathrm{j}$ are characterized by several distinct peak-valley waves. From these cycles, it is observed that the intensity of pressure fluctuation is not uniform during the revolution of the impeller at various speeds, which is mainly due to asymmetry of the flow in the impeller passages (Guo \& Maruta, 2005). In addition, when the flow from the impeller blade approaches the diffuser blade, the static pressure at the edge of impeller blade and the passage increases distinctly and causes a fluctuation in the static pressure distribution (Kang et al., 2019). however, no remarkable correlation was noticed in the time domain signals of pressure fluctuation captured at BEP at various speeds.

Pressure fluctuation signals can be evaluated in several forms. The Root Mean Square (RMS) is one of the methods used to evaluate the energy content of the signal. Any variation in the statistical properties of a signal will be reflected by RMS value. An increase in RMS magnitude may indicate the instability in the flow (Luo et al., 2015). The RMS of the signals can be calculated by the following equation:

$\mathrm{X}_{\mathrm{RMS}}=\sqrt{\frac{\mathrm{x}_{1}{ }^{2}+\mathrm{x}_{2}{ }^{2}+\mathrm{x}_{3}{ }^{2}+\ldots .+\mathrm{x}_{\mathrm{n}}{ }^{2}}{\mathrm{n}}}$

where

$\mathrm{X}_{\mathrm{RMS}}$ - root mean square values; $\mathrm{x}_{1}, \mathrm{x}_{2}, \mathrm{x}_{3} \ldots, \mathrm{x}_{\mathrm{n}}$ - samples; $\mathrm{n}$-total number of samples.

The RMS values calculated in this experiment at BEP at various speeds are given in Table 5. The RMS amplitudes were normalized with respect to the RMS value obtained at the nominal speed. The variation of normalized RMS amplitude with speed is shown in Fig. 7.

Table 5. RMS values of pressure fluctuation signals at BEP at various speeds.

\begin{tabular}{|c|c|c|}
\hline Speed $\left(\mathbf{N}_{\mathbf{n}}\right)$ & RMS in kpa & Normalized amplitude of RMS \\
\hline $0.8 \mathrm{~N}$ & 562.07 & 0.77 \\
\hline $0.9 \mathrm{~N}$ & 623.41 & 0.86 \\
\hline $\mathrm{N}$ & 728.88 & 1.00 \\
\hline $1.1 \mathrm{~N}$ & 878.43 & 1.21 \\
\hline $1.2 \mathrm{~N}$ & 1010.39 & 1.39 \\
\hline
\end{tabular}




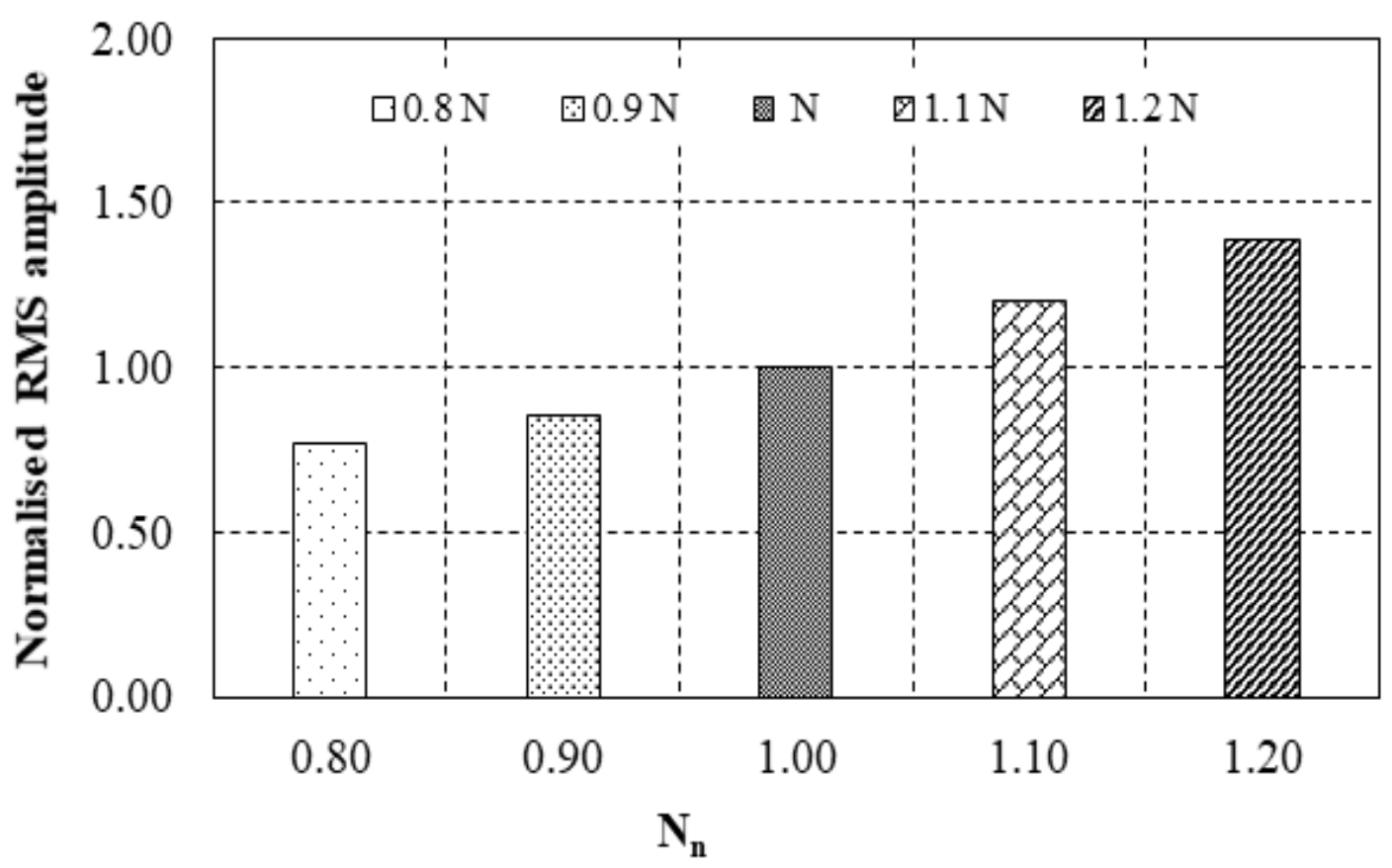

Figure 7. Variation of energy content of the signal with speed.

From Fig. 7, it can be observed that the energy content of the pressure fluctuation signal has shown a linear variation with respect to speed. The energy content of the signal at the highest speed of $1.2 \mathrm{~N}$ is 1.39 times higher than the energy content at nominal speed which indicated that the components of the pump at the delivery side and the piping system will be affected by a higher-pressure fluctuation at higher operating speeds.

\section{Fast Fourier Transformation}

The excitation mechanism due to pressure fluctuation can not be ascertained from the time-domain signals. Similarly, the RMS amplitude can only be used as a measure of average power of the signal. In general, the spectra of pressure fluctuation contain superimposition of discrete components over the broad band noise components which are generated due to unsteadiness in the flow. The frequencies of this spectra are mostly Blade Passing Frequency (BPF) due to the rotation of the impeller and its harmonics. According to Fourier's theorem any waveform, which is represented in the time domain can be converted into frequency domain.

The frequency and amplitude are the two important characteristics of the pressure fluctuation signal. So, to interpret the characteristics of pressure fluctuation and to analyze their variation with speed and stage, these timedomain signals must be converted into frequency domain. In the frequency domain analysis, the captured time domain signals are decomposed into frequency and amplitude.

Time domain signals can be converted to Frequency domain signal by Fast Fourier Transform (FFT) and it is useful for measuring the frequency content of stationary or transient signals. In fft the sequence of $\mathrm{N}$ complex numbers $\mathrm{x} 0, \mathrm{x} 1, \mathrm{x} 2 \ldots, \mathrm{xN}-1$ is transformed into the sequence of $\mathrm{N}$ complex numbers $\mathrm{X} 0, \mathrm{X} 1, \mathrm{X} 2 \ldots, \mathrm{XN}-1$ by the Discrete Fourier Transformation (DFT) according to the following formula (Christopher, 2012): 
$X_{k}=\sum_{n=0}^{N-1} x_{n} e^{-\frac{2 \pi}{N} k n}$

$X_{k}=\sum_{n=0}^{N-1} x_{n}\left[\cos \left(\frac{2 \pi}{N} k n\right)-j \sin \left(\frac{2 \pi}{N} k n\right)\right]$

where

$\mathrm{X}_{\mathrm{k}}$ - complex part of frequency domain; $\mathrm{N}$ - number of samples; $\mathrm{x}_{\mathrm{n}}$ - real part of time domain; $\mathrm{k}$ - constant; $\mathrm{n}$ count

The captured signals were divided into fifty groups with each group having 4096 samples. FFT was taken on all the fifty groups using the analysis tool available in MS-Excel. In order to reduce the uncertainties, present in the signal, an arithmetic average of all FFT amplitudes of all the groups was taken and used for analysis. Figure 8 shows spectra of pressure fluctuation at BEP at various speeds with normalized speed in X axis, frequency in $\mathrm{Y}$ axis, and amplitude in $\mathrm{Z}$ axis.

In the spectra of pressure fluctuation, several prominent peaks at about $6000 \mathrm{~Hz}$ and its harmonics were observed. Similar peaks were present in the analysis of current signature of induction motor for centrifugal pump load carried out by Luo et al. (2016). A detailed study was carried out to find source of these peaks. The results have shown that these prominent peaks may be due to structural vibration of the casing of the pump (Dhanasekaran $\&$ Kumaraswamy, 2021).

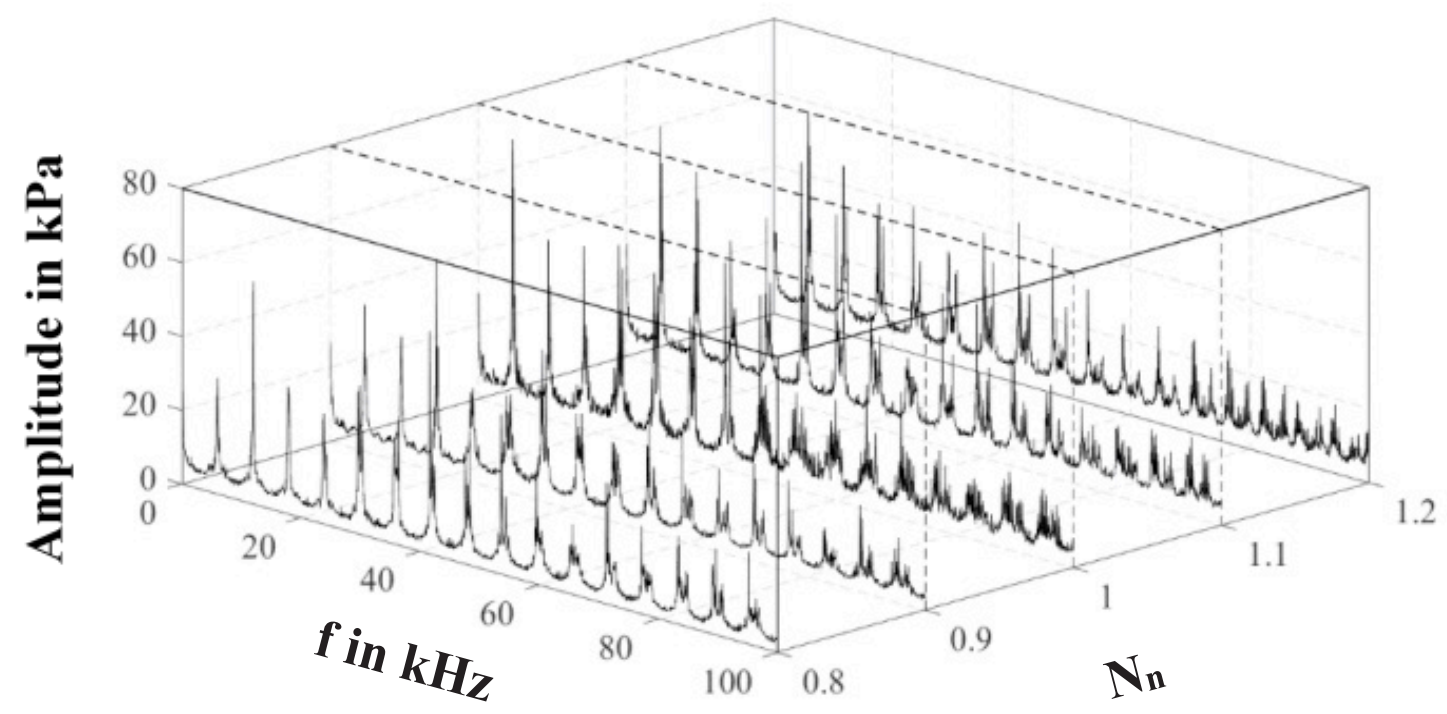


Figure 8. Spectra of pressure fluctuation at BEP at various speeds.

The Blade Passing Frequency (BPF) generated due to the rotation of the impeller, stationary diffuser and the $\mathrm{BPF}$ at the end of each stage in a multistage pump can be calculated using the following equations:

$$
\mathrm{BPF}=\mathrm{N}_{\text {actual }} \times \mathrm{Z}_{\mathrm{i}}
$$

Where

$\mathrm{N}_{\text {actual }}$ - actual speed in $\mathrm{Hz} ; \mathrm{z}_{\mathrm{i}}$ - number of vanes in the impeller

$$
\mathrm{f}_{\mathrm{d}}=\mathrm{BPF} \times \mathrm{z}_{\mathrm{d}}
$$

Where

$\mathrm{f}_{\mathrm{d}}$ - blade passing frequency at diffuser; $\mathrm{z}_{\mathrm{d}}$ - number of diffuser vanes

It was found that similar equations have been used by Nelson (1987) to calculate BPF of impeller and diffuser. It may be noted that the fluid entering one stage contains the frequency components of the previous stage. So, the frequency of pressure fluctuation (f) at each stage in a multistage pump can be calculated by the following equation:

$\mathrm{f}=\mathrm{f}_{\mathrm{d}} \times$ stage number

Where

f - frequency of pressure fluctuation in Hz; Equations (4), (5), and (6) were used to calculate BPF and its harmonic components at various stages when the pump was operated at BEP under various speeds. From the FFT spectra, the amplitude corresponding to these BPF and its harmonic components were obtained. All the harmonic components were normalized $\left(f_{n}\right)$ with respect to the first harmonic. Similarly, all the amplitudes were normalized $\left(\mathrm{P}_{\mathrm{n}}\right)$ with respect to the amplitude value obtained at stage 3 due to the fact that the stage 3 of this multistage pump experiences a flow phenomenon which is similar to any intermediate stage. The pressure fluctuation amplitudes from one-fifth $\left(1 / 5^{\text {th }}\right)$ to tenth $\left(10^{\text {th }}\right)$ harmonics were only considered for further analysis as the amplitudes beyond these limits were found to be insignificant.

\section{Effect of stage on pressure fluctuation}

The effect of stage and speed variation on the pressure fluctuation was studied by plotting the variation of pressure fluctuation at all the five stages at various speeds. Figures 9 a to 9 e have shown the variation of pressure fluctuation with frequency at various stages at various speeds along with first three prominent harmonics in a tabular column. The speeds are shown in the labels for each stage. A similar method is adopted in all the other plots. 


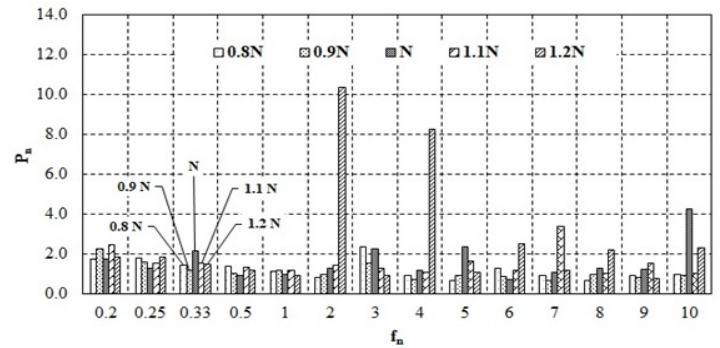

\begin{tabular}{cccc}
\hline \multicolumn{4}{c}{ Predominating harmonics at stage 1 } \\
$\mathrm{N}_{\mathrm{n}}$ & I & II & III \\
\hline 0.8 & $3^{\text {rd }}$ & $1 / 4^{\text {th }}$ & $1 / 5^{\text {th }}$ \\
0.9 & $1 / 5^{\text {th }}$ & $1 / 4^{\text {th }}$ & $3^{\text {rd }}$ \\
1.0 & $10^{\text {th }}$ & $5^{\text {th }}$ & $3^{\text {rd }}$ \\
1.1 & $7^{\text {th }}$ & $1 / 5^{\text {th }}$ & $5^{\text {th }}$ \\
1.2 & $2^{\text {nd }}$ & $4^{\text {th }}$ & $6^{\text {th }}$ \\
\hline
\end{tabular}

(a). Stage 1

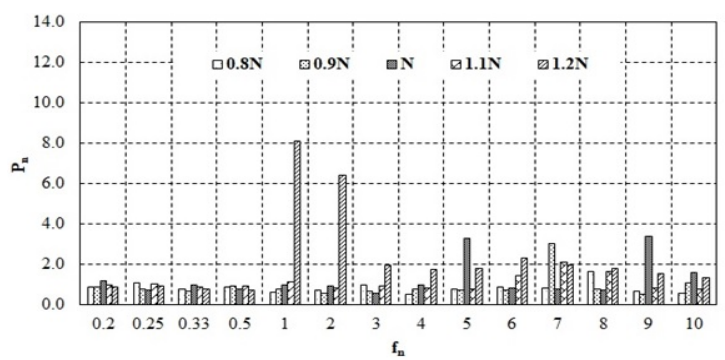

\begin{tabular}{cccc}
\hline \multicolumn{4}{c}{ Predominating harmonics at stage 2 } \\
$\mathrm{N}_{\mathrm{n}}$ & $\mathrm{I}$ & $\mathrm{II}$ & III \\
\hline 0.8 & $8^{\text {th }}$ & $1 / 4^{\text {th }}$ & $3^{\text {rd }}$ \\
0.9 & $7^{\text {th }}$ & $10^{\text {th }}$ & $1 / 2^{\text {nd }}$ \\
1.0 & $9^{\text {th }}$ & $5^{\text {th }}$ & $10^{\text {th }}$ \\
1.1 & $7^{\text {th }}$ & $8^{\text {th }}$ & $6^{\text {th }}$ \\
1.2 & $1^{\text {st }}$ & $2^{\text {nd }}$ & $6^{\text {th }}$ \\
\hline
\end{tabular}

(b). Stage 2

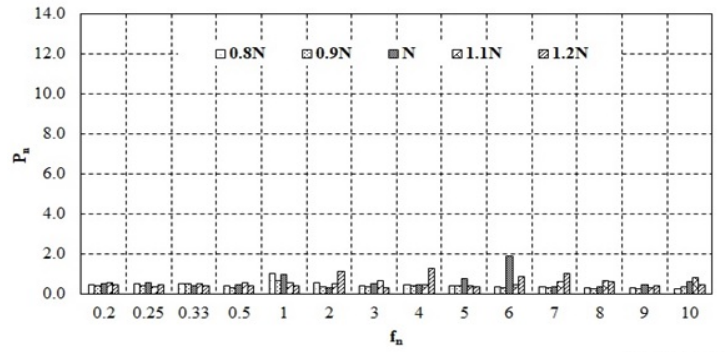

\begin{tabular}{lccc}
\hline \multicolumn{4}{l}{ Predominating harmonics at stage 3 } \\
$\mathrm{N}_{\mathrm{n}}$ & $\mathrm{I}$ & II & III \\
\hline 0.8 & $1^{\text {st }}$ & $2^{\text {nd }}$ & $1 / 4^{\text {th }}$ \\
0.9 & $1^{\text {st }}$ & $1 / 3^{\text {rd }}$ & $5^{\text {th }}$ \\
1.0 & $6^{\text {th }}$ & $1^{\text {st }}$ & $5^{\text {th }}$ \\
1.1 & $10^{\text {th }}$ & $3^{\text {rd }}$ & $8^{\text {th }}$ \\
1.2 & $4^{\text {th }}$ & $2^{\text {nd }}$ & $7^{\text {th }}$ \\
\hline
\end{tabular}

(c). Stage 3

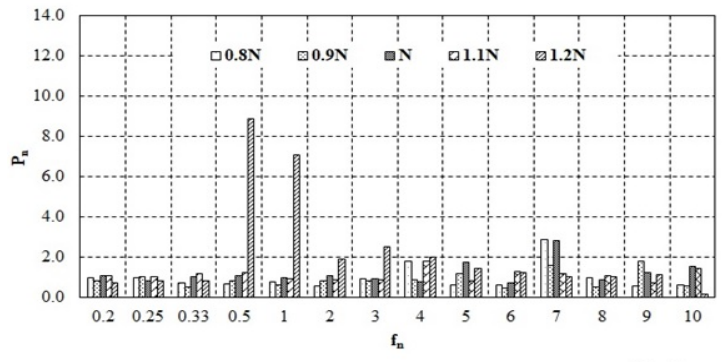

\begin{tabular}{cccc}
\hline \multicolumn{4}{c}{ Predominating harmonics at stage 4 } \\
$\mathrm{N}_{\mathrm{n}}$ & I & II & III \\
\hline 0.8 & $7^{\text {th }}$ & $4^{\text {th }}$ & $1 / 5^{\text {th }}$ \\
0.9 & $9^{\text {th }}$ & $7^{\text {th }}$ & $5^{\text {th }}$ \\
1.0 & $7^{\text {th }}$ & $5^{\text {th }}$ & $10^{\text {th }}$ \\
1.1 & $4^{\text {th }}$ & $10^{\text {th }}$ & $6^{\text {th }}$ \\
1.2 & $1 / 2^{\text {nd }}$ & $1^{\text {st }}$ & $3^{\text {rd }}$ \\
\hline
\end{tabular}

(d). Stage 4

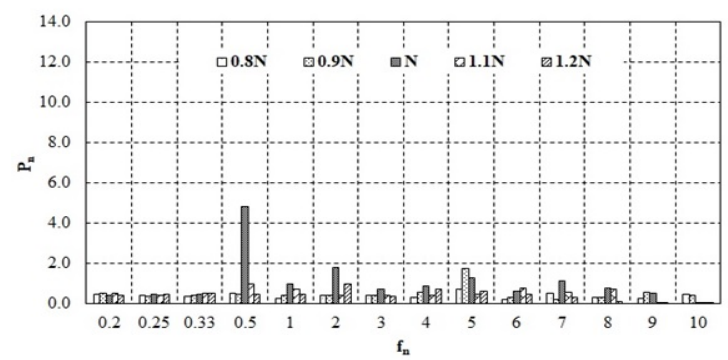

\begin{tabular}{cccc}
\hline \multicolumn{4}{c}{ Predominating harmonics at stage 5 } \\
$\mathrm{N}_{\mathrm{n}}$ & I & II & III \\
\hline 0.8 & $5^{\text {th }}$ & $7^{\text {th }}$ & $1 / 2^{\text {nd }}$ \\
0.9 & $5^{\text {th }}$ & $4^{\text {th }}$ & $9^{\text {th }}$ \\
1.0 & $1 / 2^{\text {nd }}$ & $2^{\text {nd }}$ & $5^{\text {th }}$ \\
1.1 & $1 / 2^{\text {nd }}$ & $6^{\text {th }}$ & $8^{\text {th }}$ \\
1.2 & $2^{\text {nd }}$ & $4^{\text {th }}$ & $5^{\text {th }}$ \\
\hline
\end{tabular}

(e). Stage 5

Figure 9. Variation of pressure fluctuation at BEP at the stages of ESP at various speeds. 
From the Figures 9 a to $9 \mathrm{e}$ it is observed that at stage 1 when the pump is operated at BEP at lower speed of 0.8 $\mathrm{N}$ and $0.9 \mathrm{~N}$ several predominating harmonics are subharmonics (i.e., fraction of harmonics). The effect of subharmonics is reduced when the pump is operated at its nominal speed, and most of the predominating harmonics are higher harmonics (i.e., $\geq 5$ ). At higher speed $1.1 \mathrm{~N}$ of predominating effect of subharmonics are present. At the highest speed of $1.2 \mathrm{~N}$ the predominating harmonics are integer harmonics. At stage 2 at lower speeds several predominating harmonics are subharmonics. At nominal speed and at the other higher speeds the presence of subharmonics was eliminated and most of the predominating harmonics are higher harmonics.

At stage 3 at lower speeds several predominating harmonics are subharmonics. At nominal speed and at the other higher speeds the presence of subharmonics is eliminated and most of the predominating harmonics are higher harmonics. At stage 4 the effect of subharmonics is reduced at all the speeds and the predominating harmonics at all these speed settings are higher harmonics. At stage 5 the effect of subharmonics is reduced when the pump is operated at lower speeds. Also, most of the predominating harmonics are higher harmonics. Similarly, less prominent subharmonics are present when the pump is operated at nominal speed, $1.1 \mathrm{~N}$ and $1.2 \mathrm{~N}$ and most of the predominating harmonics are higher harmonics. The pressure fluctuation study has indicated that the variation of pressure fluctuation at BEP at various stages and at various speeds is nonlinear and complex. A further analysis on the pressure fluctuation has revealed that, at lower speeds, i.e., at $0.8 \mathrm{~N}$ and $0.9 \mathrm{~N}$ the presence of sub harmonics is considerably more in stages 1 to 3 than at stages 4 and 5. At nominal speed at stage 5 the most predominating harmonic components are sub harmonic. At higher speeds i.e., at $1.1 \mathrm{~N}$ and $1.2 \mathrm{~N}$ at stages 1,4 , and 5 the sub harmonics are present in the predominating harmonics. This indicates that the pressure fluctuation can be considerably more at subharmonics level irrespective of stage and speed in the variable speed operation of the pump.

Studies have shown that the pressure fluctuations are generated not only due to the wake flow on the diffuser vanes, but also by the vortices developing at the downstream of the trailing edge due to the presence of shear layers and flow separation. Hence the wake flow is the main source of pressure fluctuations at the blade passing frequency and its harmonics (Guelich, 2010). The unsteady flow at the impeller outlet causes Rotor-Stator Interaction (RSI) which consists two different types of flows phenomena one is the potential flow due to the relative motion of the fluid between the rotating impeller and the stationary diffuser and the second is the wake flow which arises from the flow separation from the impeller (Dring et al., 1982).

The RSI induces periodic flow and periodic pressure fluctuation. Even though the influence of jet-wake flow pattern is significantly small when the pump is operated at its BEP, the asymmetrical flow in impeller passages causes the generation of pressure fluctuation. The nonlinearity in the characteristics of pressure fluctuation at various stages in the ESP are mainly due to coupling of pressure field at various stages of the ESP and the mutual interference between impeller, diffuser and return channel vanes. Similar kind of nonuniform pattern in the characteristics of pressure fluctuation can be observed in the previous research works conducted by Fu et al. (2018), Wang et al. (2018), Cavazzini et al. (2011) and Kaupert \& Staubli (1999).

The variation of maximum amplitude of pressure fluctuation at various stages was studied by plotting stages and pressure fluctuation amplitudes. Figure 10 shows the variation of maximum amplitude of pressure fluctuation at various stages at various speeds. From figure 10, it is observed that at stage 1 the maximum amplitude of pressure fluctuation occurred at $2^{\text {nd }}$ harmonic at an operating speed of $1.2 \mathrm{~N}$. At stage 2, the maximum amplitude of pressure fluctuation occurred at $1^{\text {st }}$ harmonic at an operating speed of $1.2 \mathrm{~N}$. At stage 3, the maximum amplitude of pressure fluctuation occurred at $6^{\text {th }}$ harmonic when the pump is operated at its nominal speed. At stage 4 , the maximum amplitude of pressure fluctuation occurred at $1 / 2^{\text {nd }}$ harmonic at an operating speed of $1.2 \mathrm{~N}$. At stage 5 , the maximum amplitude of pressure fluctuation occurred at $1 / 2^{\text {nd }}$ harmonic when the pump is operated at its nominal speed. 


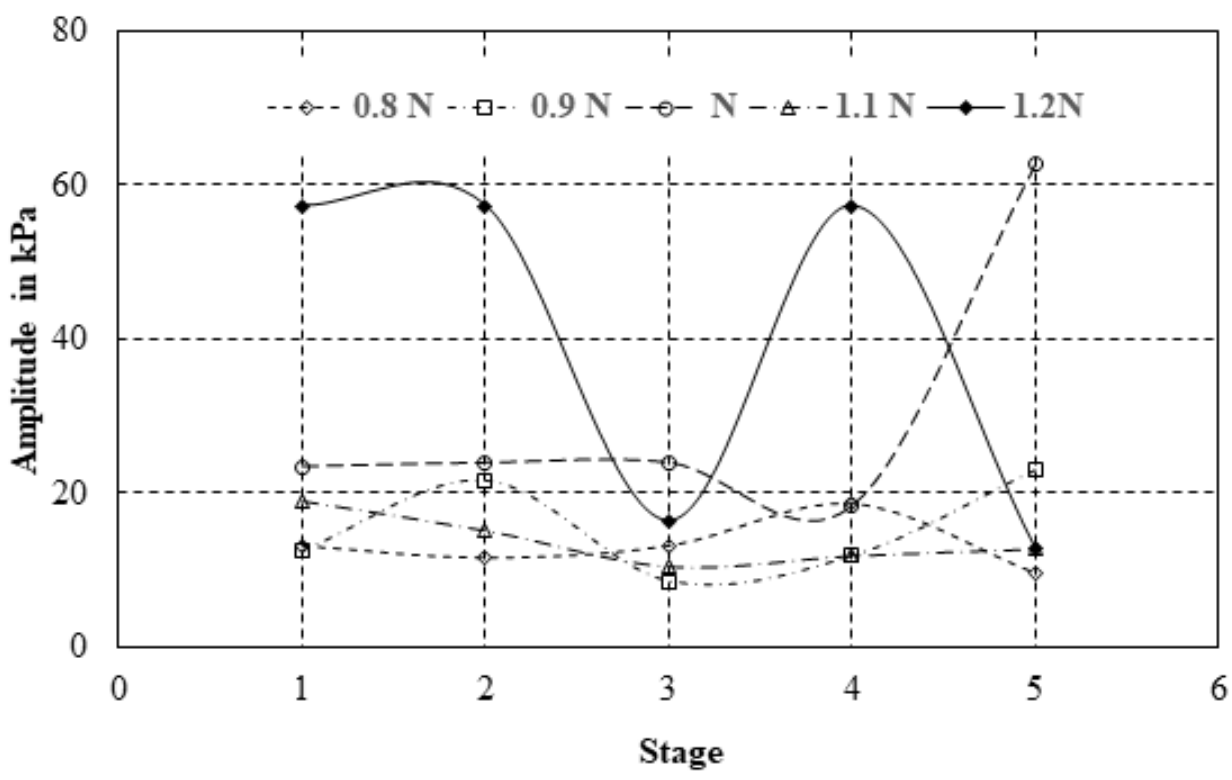

Figure 10. Variation of maximum value of pressure fluctuation with stage and speed.

The nature of flow field inside the multistage pump is obviously unsteady and complex. Moreover, the interaction between the rotating impeller and stationary diffuser and stages influences the characteristics of pressure fluctuation in a multistage pump under various speeds of operation. A stage wise pressure fluctuation study can be used for fatigue failure-based stress analysis.

\section{CONCLUSION}

The present research work studied the correlation in the characteristics of pressure fluctuation in the stages of a vertical multistage pump at BEP at various speeds to achieve an optimal pressure distribution inside the pump. Performance tests were conducted on a five-stage vertical submersible pump at various operating speeds. The performance test results have shown that the operation of the pump at various speeds was stable. The pump was operated at BEP at five chosen speeds, and the pressure fluctuation signals were captured and analyzed. Based on the study, the following conclusions have been made:

The time domain analysis of captured signals and that for two cycles have shown similar distribution of pressure fluctuation with a variation in the level of intensity at BEP of various operating speeds. This variation in the amplitude of pressure fluctuation is mainly is due to asymmetry of the flow in the impeller passages and interstage effects of various stages.

The RMS study has indicated that the amplitude of pressure fluctuation at the highest speed of $1.2 \mathrm{~N}$ is 1.39 times higher than the amplitude at nominal operating speed. The RMS values of pressure fluctuation varies linearly with respect to speed. Further, the RMS amplitudes have shown that the components at the delivery side of the pump will be subjected to periodic pressure fluctuation at the higher speeds.

The variation of amplitude of pressure fluctuation with frequency at various stages at BEP at various speeds has indicated the influence of sub harmonics in the predominating harmonic components of BPF irrespective of speed and stage, which means that BPF at the subharmonics level must also be included in the study of pressure fluctuation 
in centrifugal pumps operated at variable speed environment. The variation of maximum value of amplitude of pressure fluctuation has shown that at stage 1 the maximum amplitude of pressure fluctuation occurred at $2^{\text {nd }}$ harmonic at an operating speed of $1.2 \mathrm{~N}$ with a magnitude of $57.24 \mathrm{kPa}$. At stage 2, the maximum amplitude of pressure fluctuation occurred at $1^{\text {st }}$ harmonic at an operating speed of $1.2 \mathrm{~N}$ with a magnitude of $57.24 \mathrm{kPa}$. At stage 3 , the maximum amplitude of pressure fluctuation occurred at $6^{\text {th }}$ harmonic when the pump operated at its nominal speed with a magnitude of $23.90 \mathrm{kPa}$.

At stage 4, the maximum amplitude of pressure fluctuation occurred at $1 / 2^{\text {nd }}$ harmonic at an operating speed of $1.2 \mathrm{~N}$ with a magnitude of $57.24 \mathrm{kPa}$. At stage 5 the maximum amplitude of pressure fluctuation occurred at $1 / 2^{\text {nd }}$ harmonic when the pump was operated at its nominal speed with a magnitude of $62.68 \mathrm{kPa}$.

From the study of pressure fluctuation conducted on a multistage submersible pump at various speeds, it can be concluded that the pressure fluctuation at BPF, its harmonics and subharmonics have shown a complex pattern. This pressure fluctuation study will help for understanding the flow-induced vibration when the pump is operated near its $\mathrm{BEP}$ at various speeds. Further, these results can help the pump application engineers interested in fatigue failurebased stress analysis for improving the reliability of the multistage pumps with an aim to achieve a uniform pressure distribution inside the pump.

\section{NOMENCLATURE}

A

$\mathrm{A}_{2}$

$\mathrm{b}_{2}$

$\mathrm{d}_{2}$

$\mathrm{d}_{\mathrm{m} 2}$

$\mathrm{d}_{\mathrm{m} 3}$

$\mathrm{d}_{\mathrm{p}}$

f

$f_{d}$

$f_{n}$

g

$\mathrm{H}$

area of pipe, $\left(=\frac{\pi \times d_{p}{ }^{2}}{4}\right), \mathrm{m}^{2}$

area at impeller outlet, $\left(=\pi d_{2} b_{2}\right), \mathrm{m}^{2}$

outlet width of impeller, $\mathrm{m}$

outer diameter of impeller, $\mathrm{m}$

diameter of impeller vane at mean streamline, $\mathrm{mm}$

diameter of diffuser vane at mean streamline, $\mathrm{mm}$

diameter of pipe, $m$

frequency of pressure fluctuation, $\mathrm{kHz}$

blade passing frequency at diffuser, $\mathrm{kHz}$

normalized frequency

acceleration due to gravity, $\left(=9.81 \mathrm{~m} / \mathrm{s}^{2}\right)$

head, $\left(=\frac{P_{d}}{\rho g}+\frac{V^{2}}{2 g}+z\right), \mathrm{m}$ 
$\mathrm{k}$

$\mathrm{N}_{\mathrm{sh}}$

$\mathrm{N}$

$P_{d}$

$P_{\text {in }}$

$P_{n}$

$P_{\text {out }}$

Q

$\mathrm{U}_{2}$

V

$\mathrm{X}_{\mathrm{RMS}}$

$\mathrm{X}_{\mathrm{k}}$

$\mathrm{X}_{1}, \mathrm{X}_{2}, \mathrm{X}_{3} \ldots, \mathrm{X}_{\mathrm{n}}$

$\mathrm{X}_{\mathrm{n}}$

Z

$\mathrm{Zi}_{\mathrm{i}}$

$Z_{d}$

$\mathrm{Zs}_{\mathrm{s}}$

$\eta_{\mathrm{o}}$ constant

speed, nominal speed, Hz, number of samples

shape number, $\left(=\frac{10^{3} \times N \sqrt{\frac{Q}{10^{3}}}}{\left(g \frac{H}{z_{s}}\right)^{\frac{3}{4}}}\right)$

total number of samples and count

delivery pressure, $\mathrm{kp} / \mathrm{cm}^{2}, \mathrm{~N} / \mathrm{m}^{2}$

input power, $\mathrm{kW}$

normalized amplitude of pressure fluctuation

output power of pump, $\left(=\frac{\rho g Q H}{1000}\right), \mathrm{kW}$

discharge, flow rate, $1 \mathrm{ps}$

circumferential speed of impeller at outlet, $\left(=\pi d_{2} N\right), \mathrm{m} / \mathrm{s}$

velocity of flow, $\left(=\frac{Q}{A}\right), \mathrm{m} / \mathrm{s}$

root mean square values

complex part of frequency domain

samples

real part of time domain

height of pressure gauge from water level, m

number of vanes in the impeller

number of diffuser vanes

number of stages

overall efficiency, wire to water efficiency, $\left(=\frac{P_{o u t}}{P_{i n}} \times 100\right), \%$ 


$$
\begin{array}{ll}
\rho & \text { density of water, }\left(=1000 \mathrm{~kg} / \mathrm{m}^{3}\right) \\
\varphi & \text { flow coefficient, }\left(=\frac{Q}{10^{3} U_{2} A_{2}}\right) \\
\psi & \text { head coefficient, }\left(=\frac{2 g H}{U_{2}^{2}}\right)
\end{array}
$$

\section{ACKNOWLEDGEMENTS}

The authors express their sincere gratitude to the then Hydroturbomachines lab, Department of Mechanical Engineering, Indian Institute of Technology Madras, Chennai, for providing the facility to conduct the experiments and M/S Flowell pumps Hyderabad, India, for supplying the multistage submersible pump required for this work as a special product.

\section{REFERENCES}

Brennen, C. E. 1994. Hydrodynamics of pumps. Concept ETI Inc./Oxford University Press, White River Junction, VT/Oxford, UK.

Cavazzini, G., Pavesi, G. \& Ardizzon, G. 2011. Pressure instabilities in a vaned centrifugal pump. Proc. IMechE Part A: Journal of Power and Energy 0: 1-10.

Christopher, S. 2012. Correlation of cavitation noise and vibration in radial flow pump for different leadingedge profiles of the vane. Ph. D. thesis, Hydroturbomachines lab., Indian Institute of Technology Madras, Tamilnadu, India.

Christopher, S. \& Kumaraswamy, S. 2013. Identification of critical net positive suction head from noise and vibration in a radial flow pump for different leading-edge profiles of the vane. Journal of Fluids Engineering 135: 121301-1- 121301-15.

Dhanasekaran, A. \& Kumaraswamy, S. 2017. Evaluating the performance of electric submersible pump under various speeds of operation. Imperial Journal of Interdisciplinary Research 3 (4): 1332-1337.

Dhanasekaran, A. \& Kumaraswamy, S. 2021. Eigen frequency analysis of diffuser casing of a multistage pump. Sādhanā, 46: 123: 1-12.

Dring, R.P., Joslyn, H.D., Hardin, L.W. \& Wagner, J.H. 1982. Turbine rotor-stator interaction. ASME Journal of Engineering for Power 104:729-742.

Feng, J., Benra, F.K. \& Dohmen, H.J. 2009. Investigation of turbulence and blade orientation effects in a radial diffuser pump by laser doppler velocimetry. Proc. IMechE Part A: J. Power and Energy 223: 991-999.

Fiaschi, D., Graniglia, R. \& Manfrida, G. 2005. Improving the effectiveness of solar pumping systems by using modular centrifugal pumps with variable rotational speed. Solar Energy 79: 234-244.

Fu, D.C., Wang, F.J., Zhou, P.J., Xiao, R.F. \& Yao, Z.F. 2018. Impact of impeller stagger angles on pressure fluctuation for a double-suction centrifugal pump. Chinese Journal of Mechanical Engineering 31: 10: 1-14.

Guelich, J.F. \& Bolleter, U. 1992. Pressure pulsations in centrifugal pumps. Transactions of the ASME 114: 272279. 
Gülich, J.F. 2010. Centrifugal Pumps second Edition. Springer.

Guo, S. \& Maruta, Y. 2005. Experimental investigations on pressure fluctuations and vibrations of the impeller in a centrifugal pump with vaned diffuser. JSME International Journal Series B 48 (1): 136-143.

IS 9137. (1978). Code for acceptance tests for centrifugal, mixed flow and axial pumps - class C, Bureau of Indian Standards.

Kang, Y., Liu, S., Zou, W. \& Hu, X. 2019. Numerical investigation on pressure pulsation characteristics and radial force of a deep-sea electric lifting pump at off-design conditions. Shock and Vibration 2019:1-17.

Kaupert, K.A. \& Staubli, T. 1999. The unsteady pressure field in a high specific speed centrifugal pump impellerPart II: Transient hysteresis in the characteristic. Journal of Fluids Engineering 121: 627-632.

Kumaraswamy, S. 1986. Cavitation studies of centrifugal pumps. Ph. D. thesis, Hydroturbomachines lab., Indian Institute of Technology Madras, Tamilnadu, India.

Liu, Y., Leqin, W., Zuchao, Z. 2016. Experimental and numerical studies on the effect of inlet pressure on cavitating flows in rotor pumps, Journal of Engineering Research. 4.

Liu, H., Xia, R., Wang, K., Jing, Y. \& He, X. 2019. Experimental analysis on pressure fluctuation characteristics of a centrifugal pump with vaned-diffuser. Water 126: 1-12.

Luo, Y., Sun, H., Yuan, S. \& Yuan, J. 2015. Research on statistical characteristics of vibration in centrifugal pump. Rev. Téc. Ing. Univ. Zulia 38 (1): 49-61.

Luo, Y., Yuan, S., Yuan, J. \& Sun, H. 2016. Induction motor current signature for centrifugal pump load. J Mechanical Engineering Science IMechE Part C 230 (11): 1890-1901.

Luo, K., Wang, Y., Liu, H., Chen, J., Li, Y. \& Yan, J. 2019. Effect of suction chamber baffles on pressure fluctuations in a low specific speed centrifugal pump. Journal of Vibroengineering 21(5): 1441-1455.

Nelson, W.E. 1987. Pump vibration analysis for the amateur. Proceedings of the Fourth International Pump Symposium, Texas A \& M University 109-119.

Posa, A. \& Lippolis, A. 2019. Effect of working conditions and diffuser setting angle on pressure fluctuations with in a centrifugal pump. International Journal of Heat and Fluid Flow 75: 44-60.

Rakibuzzaman, Suh, S., Wuk, K., Kim, H., Cho, M. \& Yoon, I. 2015. A study on multistage centrifugal pump performance characteristics for variable speed drive system. Procedia Engineering 105: 270-275.

Robinett, F.L., Gulich, J.F. \& Kaiser, T. 1999. Vane pass vibration-source, assessment and correction- A practical guide for centrifugal pumps. Proceedings of the $16^{\text {th }}$ International Pump Users Symposium 121-138.

Si, Q., Yuan, S., Yuan, J. \& Liang, Y. 2013. Investigation on flow-induced noise due to backflow in low specific speed centrifugal pumps. Advances in Mechanical Engineering 2013: 1-12.

Spence, R. \& Teixeira, J. 2009. A CFD parametric study of geometrical variations on the pressure pulsations and performance characteristics of a centrifugal pump. Journal of Computers and Fluids 38(6): 1243-1257.

Stel, H., Sirino, T., Ponce, F.J., Chiva, S. \& Morales, R.E.M. 2015. Numerical Investigation of the flow in a multistage electric submersible pump. Journal of Petroleum Science and Engineering 136: 41-54.

Wang, H. \& Tsukamoto, H. 2003. Experimental and numerical study of unsteady flow in a diffuser pump at offdesign conditions, Journal of Fluids Engineering 125: 767-778.

Wang, K., Zhang, Z., Xia, C. \& Liu, Z. 2018. Experimental investigation of pressure fluctuation, vibration, and noise in a multistage pump. Shock and Vibration 2018: 1-13.

Wu, D., Ren, Y., Mou, J. \& Gu, Y. 2017. Investigation of pressure pulsations and flow instabilities in a centrifugal pump at part-load conditions. International Journal of Fluid Machinery and Systems 10(4): 355362. 
Xia, L., Deyou, Zhou, L., Wang, P. \& Chen, Y. 2015. Optimization of a seawater once-through cooling system with variable speed pumps in fossil fuel power plants. International Journal of Thermal Sciences 91: 105112.

Zhang, N., Jiang, J., Gao, B. \& Liu, X. 2020. DDES analysis of unsteady flow evolution and pressure pulsation at off-design condition of a centrifugal pump. Renewable Energy 153: 193-204.

Zhou, W.J., Xue-Song, W., Guang-Kuan, W., Wan-Jiang, L \& Le-Qin, W. 2015. Numerical research on dynamic lateral vibration of a pump turbine's shaft system, Journal of Engineering Research 3:127-148. 